\title{
Una visión de la locura: el caso Breton
}

Diferentes corrientes de pensamiento, artísticas e ideológicas han abogado por una visión de la locura como un estado mental propicio para la creación, un estado que posibilita el acceso a un plano alternativo que permite aflorar ciertas aptitudes por lo general constreñidas. Ya en la modernidad los autores del romanticismo, siempre en busca de la inspiración arrebatadora que sume al sujeto en un estado alterado que impele a la creación, son un claro exponente de tal creencia, de hecho tienen a la locura como el fundamento positivo de la normalidad y no como una elaboración secundaria, deficitaria; y más recientemente simbolistas y dadaístas son de la misma opinión. Claro está que todos son conscientes del sufrimiento que causa la locura a quien la padece, pero, como décadas más tarde hará la antipsiquiatría, creen que la culpa de tal sufrimiento es externa, social, de un entorno que no logra asimilar al diferente, al loco.

En esta misma línea se sitúa el surrealismo, que entiende la locura como un estado privilegiado cuyo delirio es fuente de placer a la vez que materia prima para la creación artística y defiende su valor lamentando que sea objeto de persecución por los órganos represores de la sociedad: Breton afirma que «todos sabemos que los locos deben su internamiento a un reducido número de actos jurídicamente reprobables, y que, en la ausencia de estos actos, su libertad (la parte visible de su libertad) no sería puesta en tela de juicio» ${ }^{1}$; y en el tercer número de La révolution surréaliste se publica una carta dirigida a los médicos jefe de los manicomios, escrita por Desnos pero asumida por todo el grupo surrealista, donde se discute el valor de la ciencia psiquiátrica para entender el espíritu humano tachándola de simple mecanismo represor, pues no hay un intento serio de acercamiento al loco, a sus expresiones, a las que califican de jerga ininteligible, de ensalada de palabras: «No admitimos que se obstaculice el libre desarrollo de un delirio, tan legítimo, tan lógico como cualquier otra sucesión de ideas o de actos humanos. La represión de las reacciones antisociales es tan quimérica como inaceptable. Todos los actos individuales son antisociales. Los locos son las víctimas individuales por excelencia de la dictadura social; en nombre de esta individualidad que es lo propio del hombre, exigimos que se libere a estos galeotes de la sensibilidad, pues además no es potestad de las leyes encerrar a todos los hombres que piensan y actúan» ${ }^{2}$.

Y dentro de la locura el surrealismo tiene a la histeria como modelo de toda creación, Breton y Aragon, situándose en un polo de la dicotomía entre la histeria

\footnotetext{
Breton, A. (1924), «Manifiesto del surrealismo», en Manifiestos del surrealismo, Madrid, Visor, 2002. «Lettre aux médecins-chefs des asiles de fous», La révolution surréaliste, 3, 1925.
} 
como obstáculo y la histeria asumida y superada en la expresión estética, escriben un texto que se enfrenta al punto de vista médico, denigrando particularmente a Babinski, que sólo sabe ver en la histeria una mera enfermedad dejando a un lado su potencial creativo que le ha hecho mutar a través de los tiempos despistando a los teóricos que han intentado constreñirla en un tipo clínico; en este artículo la definen como el mayor descubrimiento poético de finales del siglo XIX y afirman que «la histeria es un estado mental, más o menos irreducible, que se caracteriza por la subversión de las relaciones que se establecen entre el sujeto y el mundo moral del cual cree depender [...]. Este estado mental se funda en la necesidad de una seducción recíproca que explica los milagros apresuradamente aceptados de la sugestión (o contrasugestión) médica. La histeria no es un fenómeno patológico y a todos los efectos puede considerarse como un medio supremo de expresión» ${ }^{3}$.

Claro está que estas afirmaciones generan la reacción del cuerpo médico, exacerbada por la lectura de las siguientes frases de Nadja: «Yo sé que si estuviera loco, tras llevar internado algunos días, aprovecharía alguna mejoría de mi delirio para asesinar a sangre fría al primero que se pusiera a mi alcance, al médico a poder ser» ${ }^{4}$; frases intercaladas en un discurso del narrador que cataloga a los manicomios como fábricas de locos, en los que es fácil entrar pero casi imposible salir, más difícil que de un convento, y que denuncia la detestable frecuencia de los internamientos arbitrarios. Tras haber leído la novela y probablemente los artículos mencionados, Abély escribe en Annales médico-psychologiques ${ }^{5}$ que el estamento médico debería tomar cartas en el asunto y pedir la retirada de la novela al editor además de demandar judicialmente al autor por difamación e incitación al asesinato; y este artículo suscita una reunión de la Société médico-psychologique en la que se pregunta sobre el vínculo existente entre el estado mental de los surrealistas y las características de sus obras, a lo que Janet responde que «las obras de los surrealistas son, ante todo, confesiones de seres obsesos y dubitati$\operatorname{vos} »^{6}$. A estas reacciones Breton responde en un artículo en el que proclama la necesidad de «alzarnos contra el insoportable, contra el creciente abuso de poder de cierta gente que cada vez consideramos menos médicos y más carceleros y, sobre todo, abastecedores de prisiones y cadalsos» ${ }^{7}$, cerrando así por su parte un

BReton, A.; ARAgOn, L., «Le cinquantenaire de l'hystérie (1878-1928)», La révolution surréaliste, 11, 1928.

BRETon, A. (1928), Nadja, Madrid, Cátedra, 2000.

ABÉLY, P., «Légitime défense», Annales médico-psychologiques, 1929.

6 Cit. en Breton, A. (1930), «Segundo manifiesto del surrealismo», en Manifiestos del surrealismo, Madrid, Visor, 2002.

BRETON, A., «La médecine mental devant le surréalisme», Le surréalisme au service de la révolution, 2 , 1930. 
asunto que se había abierto años antes en el Congreso Internacional de Psiquiatría que tuvo lugar en Blois, en 1927, y donde en su sesión inaugural Georges Raviat pronunció una conferencia titulada La noción de responsabilidad en la práctica médica en la que arremetía contra periodistas y magistrados que osaban conculcar su derecho inalienable a disponer de la libertad de quienes estaban a su cargo.

Todo este interés por la locura, y particularmente por la histeria, no es algo extravagante o arbitrario para los integrantes del movimiento surrealista sino fundamental pues sus autores trabajan con los automatismos psíquicos y la histeria es la expresión física de un automatismo psíquico, y por eso la entienden como un mecanismo expresivo más del ser humano que ante la decepción, la frustración, la agresión o el sufrimiento elige una sintomatología para hacerse escuchar, a pesar de que a veces le pueda conducir al desequilibrio, a la disociación mental o incluso a la muerte. Esto nos remite a la famosa frase con la que Breton acaba su Nadja: «La belleza será CONVULSIVA o no será» ${ }^{8}$, que se retrotrae así a lo histérico convulso, es decir, a esa capacidad de la histeria para subvertir el orden imperante pues para él, como surrealista, la histeria, a la que separa de otras especies de locura, es un lenguaje, una forma de expresión, un trabajo poético cuya forma subversiva pone en solfa las formas literarias y artísticas admitidas para sacar a la luz un nuevo universo formal.

Claro que no todos los hombres caen en la locura, y menos de una forma premeditada, pero sí soñamos todos y el sueño puede entenderse como una especie de locura transitoria, configurándose así como un mecanismo para acceder a un espacio privilegiado. Lo que Breton busca con el surrealismo, tal como lo expone en su primer Manifiesto, es superar la aparente contradicción entre el estado del sueño y el de la vigilia elaborando un nuevo estado, una especie de realidad absoluta, es decir, una superrealidad. Nunca deja de estar convencido de que ha de existir cierto punto en el espíritu desde el cual vida y muerte, real e imaginario, pasado y futuro, sensación y representación, razón y locura, dejen de percibirse como contradicciones, como dicotomías que entorpecen el pensamiento.

El surrealismo mismo se define como «un automatismo puro que se propone expresar, de forma verbal o de cualquier otra, el funcionamiento real del pensamiento. Es un dictado del pensamiento, sin la intervención reguladora de la razón, ajeno a toda preocupación estética o moral» ${ }^{9}$. En este sentido el pintor ostenta una libertad absoluta para dejar que el pincel se mueva por la tela y haga surgir así formas provenientes directamente de lo inconsciente, y una técnica análoga en el campo literario es la escritura automática, en la que sin ningún guión preconcebi-

Breton, A. (1928), Nadja, Madrid, Cátedra, 2000.

Breton, A. (1924), «Manifiesto del surrealismo», en Manifiestos del surrealismo, Madrid, Visor, 2002. 
do se deja correr la pluma por el papel escribiendo lo primero que venga a la mente, sin censuras de tipo alguno. En esta técnica tan apreciada se observa claramente la influencia del psicoanálisis pues es un trasunto de la asociación libre en que se basa el método freudiano como mecanismo para recoger elementos que servirán para construir la llamada novela psicoanalítica.

De hecho, en el movimiento surrealista se aprecia la huella del psicoanálisis por todas partes pues sus conceptos suponen una mina: Edipo, el simbolismo sexual y la interpretación de los sueños son fuente de inspiración. Por otro lado, el mismo Breton, que estudia medicina aunque sin llegar a licenciarse, recurre al psicoanálisis para entender a los soldados traumatizados internados en el hospital de Nantes al que le destinan en la I Guerra Mundial, siendo testigo de ataques histéricos en los convalecientes, condenados a revivir los horrores de las trincheras en terribles pesadillas o torturados por la visión de ciertos objetos que les provocan miedos indecibles; tal experiencia le empuja a visitar la Salpêtrière en 1917 convirtiéndose en asistente temporal de Babinski, y posiblemente esa experiencia que le permite apreciar de primera mano el estado de abandono psicológico en el que las instituciones médicas dejan a los soldados afectados por neurosis de guerra le hace aborrecer tanto la guerra misma como estas instituciones. Y hay que recordar que no sólo Breton tiene una formación médica sino también muchos otros integrantes del movimiento surrealista, como Aragon, Boiffard, Ernst o Naville, y muchos de ellos se psicoanalizan, como Crevel, Queneau, Artaud, Leiris o Bataille; y las teorías psicológicas que de esta manera van asimilando las aplican a sus actividades.

Pero el automatismo, central en el surrealismo, es simplemente un mecanismo y a los mismos surrealistas sólo les interesa como puerta de entrada a los mecanismos profundos de la mente; además muchas veces se trata de un automatismo un tanto dirigido, y los productos surrealistas en multitud de ocasiones no están en consonancia con el criterio estético de sus autores ni de sus correligionarios, por lo que el asunto de que se trata se dirime en otro campo. No tiene tanto que ver con exprimir la capacidad de asociación libre del autor para evacuar elementos que conformen una obra más o menos sorprendente, extravagante o audaz, sino que lo importante es darse cuenta de que como Breton mismo afirma se trabaja con la materia prima del lenguaje: «¿De qué se trataba pues? Nada menos que de volver a descubrir el secreto de una lengua cuyos elementos dejaran de comportarse como restos de naufragio en la superficie de un mar muerto. Para ello era necesario sustraer el lenguaje al uso de día en día más utilitario que se le daba, lo cual constituía el único medio de emancipar las palabras y de devolverles toda su fuerza ${ }^{10}$. Desde 
el momento en que se toma conciencia de esto, de que todos tenemos la llave del depósito en el que guardamos los secretos de la lengua, cualquier procedimiento es secundario pues cualquiera nos puede servir para expresarnos.

No puedo abandonar este asunto sin precisar que para la mayoría de sus artífices, el movimiento, sus técnicas, sus obras e incluso esa conciencia de la fuerza del lenguaje que poseemos no son nada más que la herramienta necesaria para revolucionar los espíritus, una especie de carga de profundidad que penetra en nuestra mente y nos induce más tarde o más temprano a abandonar este mundo burócrata y ruin por otro. De hecho en su Segundo manifiesto Breton llama a las armas: «Todo está aún por hacer, todos los medios son buenos para aniquilar las ideas de familia, patria y religión. [...]. Y como sea que del grado de resistencia que esta idea superior [la surrealista] encuentre depende el avance más o menos seguro del espíritu hacia un mundo que, al fin, resulte habitable es comprensible que el surrealismo no tema adoptar el dogma de la rebelión absoluta, de la insumisión total, del sabotaje en toda regla, y que tenga sus esperanzas puestas únicamente en la violencia. El acto surrealista más puro consiste en bajar a la calle, revólver en mano, y disparar al azar, mientras a uno le dejen, contra la multitud. Quien no haya tenido, por lo menos una vez, el deseo de acabar de esta manera con el despreciable sistema de envilecimiento y cretinización imperante, merece un sitio entre la multitud, merece tener el vientre a tiro de revólver» ${ }^{11}$. Tal diatriba la dirige Breton a los jóvenes, los puros, los únicos que pueden enarbolar con éxito esa bandera de la liberación del pensamiento, y será ensalzada por Benjamin al recordar que, desde Bakunin, Europa carece de un concepto radical de libertad y que los surrealistas son los primeros en destruir el ideal liberal-moral-humanista convencidos de que es posible una libertad que comprada a un alto precio se pueda disfrutar sin restricciones, sin cálculos programáticos.

Ángel Cagigas

11 BREton, A. (1930), «Segundo manifiesto del surrealismo», en Manifiestos del surrealismo, Madrid, Visor, 2002. 